\title{
Quality of Service pada Virtual Local Area Network
}

\author{
Endrico Kurniawan Bura ${ }^{1}$, Rissal Effendi ${ }^{2}$ \\ 1,2 Prodi S1 Teknik Informatika, Fakultas Teknologi Informasi, Universitas Kristen Satya Wacana Salatiga, Indonesia
}

\section{A R T I C L E I N F O}

\section{Article history:}

Received September 28, 2021

Revised September 30, 2021

Accepted November 30, 2021

Available online December 25, 2021

Kata Kunci:

VLAN, RTT, Packet Loss, TTL

Keywords:

VLAN design, RTT, Packet loss, TTL

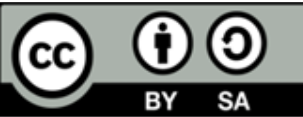

This is an open access article under the CC BY-SA license.

Copyright $@ 2021$ by Author. Published by Universitas Pendidikan Ganesha.

\section{A B S T RA C T}

VLANs are logically independent parts of the network. Packages spend much time moving to their destinations and change frequently. The network quality is not good, and the address to be addressed has a high delay. Therefore, this network can be said to be unstable. This research aims to design a network system. Internet services at this school use an Internet Service Provider (ISP). This type of research is development. The design method used in this research is the PPDIOO method. The phases in the PPDIOO method are Plan, Prepare, Design, Implement, Operate, Optimize. The methods used to collect data are questionnaires, observations, and interviews. The instrument used in this research is a questionnaire. The technique used to analyze the data is descriptive qualitative and quantitative analysis. The results of designing a virtual local area network (VLAN) obtained the highest mean round-trip time of $19.16 \mathrm{~ms}$. So for the average packet loss rate of $2.64 \%$, the packet loss results of $2.64 \%$ are included in the (Very Good) category. In addition, the median survival time is $126.5 \mathrm{~ms}$, so from the results of this test, the virtual local area network (VLAN) design is feasible to implement.

\section{PENDAHULUAN}

Dengan kemajuan teknologi jaringan komputer, maka diperlukan adanya sistem manajemen jaringan yang baik. Manajemen jaringan dapat memonitor kondisi yang ada di jaringan, sehingga dapat menghindari dan meminimalkan kesalahan yang terjadi (Moedjahedy, 2016; Rupilele \& Palilu, 2019). VLAN merupakan suatu model jaringan yang tidak terbatas pada lokasi fisik seperti LAN. Hal ini mengakibatkan suatu network dapat dikonfigurasi secara virtual tanpa harus menuruti lokasi fisik peralatan (Schrammel et al., 2021; Toyoda et al., 2021). Penggunaan VLAN akan membuat pengaturan jaringan menjadi sangat fleksibel, sehingga dapat dibuat segmen yang bergantung pada organisasi atau departemen, tanpa bergantung pada lokasi workstation (Nourildean et al., 2021; Tulloh et al., 2015). Perbedaan yang sangat jelas dari model jaringan Local Area Network dengan Virtual Local Area Network adalah bahwa bentuk jaringan dengan model Local Area Network sangat bergantung pada letak/fisik dari 
workstation, serta penggunaan hub dan repeater sebagai perangkat jaringan yang memiliki beberapa kelemahan (Li et al., 2021; Qiang, 2021). Sedangkan yang menjadi salah satu kelebihan dari model jaringan dengan VLAN adalah tiap-tiap workstation/user yang tergabung dalam satu VLAN/ bagian (organisasi atau kelompok) dapat tetap saling berhubungan walaupun terpisah secara fisik.

Berdasarkan hasil pengamatan yang dilakukan di SMKN 2 Magelang ditemukan bahwa paket menghabiskan banyak waktu berpindah ke tujuan dan sering berubah. Kualitas jaringan yang tidak baik dan alamat yang akan dituju memiliki delay yang tinggi. Oleh karena itu, jaringan ini dapat dikatakan tidak stabil. Pengamatan lebih jauh pada jaringan administrasi, waktu yang dibutuhkan sebuah paket untuk melakukan perjalanan ke tujuannya bukan hanya besar dan perubahannya sangat besar, tetapi juga menjelaskan ketidakstabilan pada jaringan. Perencanaan perlu dilakukan untuk mencapai suatu tujuan. Perencanaan terhadap sebuah penelitian diawali dengan adanya suatu masalah dalam suatu tempat. Dalam prosesnya, analisis struktur jaringan komputer lama dilakukan, yang mengakibatkan masalah seperti aliran transfer data yang kurang optimal dan dan sistemnya kurang stabil.

Jaringan komputer merupakan kursus penting pada banyak sekolah teknik, baik itu ilmu komputer, teknik elektro, atau ilmu informasi. Tujuan yang dinyatakan bervariasi dari satu kursus ke kursus lainnya. Beberapa unsur umum tujuan mata kuliah dapat diringkas sebagai berikut. a. Mahasiswa menguasai dasar-dasar jaringan komputer modern; b. Siswa belajar menggunakan bahasa pemrograman untuk mengembangkan aplikasi web; c. Mahasiswa memahami arsitektur umum jaringan komputer dan prinsip kerja protokol jaringan komputer berlapis; d. Mahasiswa dapat mengidentifikasi dan menjelaskan topik hangat di jaringan komputer, seperti keamanan dan kualitas layanan (Hertanto, 2021; Zaus \& Krismadinata, 2018). Jaringan komputer adalah koneksi dari 2 atau lebih perangkat yang terhubung secara fisik dan logis sehingga dapat saling bertukar data (Nugroho \& Kurniawan, 2018; Rohman \& Salahuddin, 2018). Jika perangkat di jaringan dapat bertukar data dan berbagi sumber daya yang mereka miliki, maka jaringan komputer dapat diartikan sebagai terhubung. Jaringan komputer adalah "interkoneksi" antara 2 komputer autonomous atau lebih, yang terhubung dengan media transmisi kabel atau tanpa kabel (wireless). Autonomous adalah apabila sebuah komputer tidak melakukan kontrol terhadap komputer lain dengan akses penuh, sehingga dapat membuat komputer lain restart, shutdown, kehilangan file atau kerusakan system (Dina \& Manivannan, 2021; Wongkar et al., 2015).

Pemanfaatan teknologi jaringan komputer sebagai media komunikasi data hingga saat ini semakin meningkat. Penggunaan jaringan komputer ini digunakan untuk berbagi resource sharing secara efisien dari segi waktu dan tidak terbatas pada jarak yang jauh (Shandilya et al., 2022; Zhu \& Luo, 2021). Kebutuhan atas penggunaan bersama resources yang ada dalam jaringan baik software maupun hardware telah mengakibatkan timbulnya berbagai pengembangan teknologi jaringan itu sendiri (Burik, 2021; Gunawan et al., 2021; Ogelman et al., 2018). Seiring dengan semakin tingginya tingkat kebutuhan dan semakin banyaknya pengguna jaringan yang menginginkan suatu bentuk jaringan yang dapat memberikan hasil maksimal baik dari segi efisiensi maupun peningkatan keamanan jaringan itu sendiri. Quality of Service (QoS) adalah teknologi yang memungkinkan administrator jaringan untuk menangani berbagai efek kemacetan pada aliran paket berbagai layanan untuk mengoptimalkan penggunaan sumber daya jaringan alih-alih meningkatkan kapasitas fisik jaringan (Kumar et al., 2021; Slimen et al., 2021). Tujuan dari mekanisme QoS adalah untuk mempengaruhi setidaknya satu dari empat parameter dasar QoS yang telah ditentukan (Hailu et al., 2020).

Berdasarkan latar belakang, dilakukan penelitian pada jaringan internet SMKN 2 Magelang dengan mengguji kualitas layanan internet menggunakan parameter uji packet loss, Round trip time dan Time To Live agar dapat menjadi bahan informasi dan kajian bagi pihak pengelola terhadap kualitas jaringan internet SMKN 2 Magelang untukmmenunjang kebutuhan akan teknologi jaringan yang lebih baik, maka perlu dibuat suatu sistem untuk mengatasi permasalahan di atas dengan membuat jaringan VLAN. Tujuan penelitian ini yaitu merancang sebuah sistem jaringan. Melalui tahapan penelitian yang dilakukan, dapat dihasilkan desain dan analisis sistem jaringan komputer. Oleh karena itu, sistem jaringan komputer ini diharapkan dapat membantu seluruh staf, guru, dan siswa dalam mengakses dan menggunakan jaringan komputer yang telah diterapkan di SMKN 2 Magelang.

\section{METODE}

Jenis penelitian ini yaitu pengembangan. Metode perancangan yang dilakukan dalam penelitian menggunakan metode PPDIOO. Metode PPDIOO adalah metode yang dikembangkan oleh CISCO, metode ini mampu memberikan langkah-langkah kunci dalam keberhasilan perencanaan jaringan, baik itu dalam tahapan desain, implementasi dan operasional. Fase-fase yang ada dalam metode PPDIOO ini adalah Plan, Prepare, Design, Implement, Operate, Optimize (Solikin, 2017). Pada tahap perencanaan (plan) dilakukan dengan menganalisis masalah yang sedang terjadi, merencanakan kebutuhan network, melakukan 
analisis, dan perencanaan waktu pengerjaan proyek. Tahap desain adalah proses mengubah kebutuhan. Tahap perencanaan ini menjadi desain sistem yang benar-benar diimplementasikan. Pada tahap operate inilah sebuah sistem jaringan secara keseluruhan diterapkan berdasarkan tahap design yang telah dibuat. Tahap optimasi dilakukan untuk mengoptimalkan sistem ketika kinerjanya tidak optimal karena adanya masalah pada sistem. Metode yang digunakan untuk mengumpulkan data yaitu kuesioner, observasi, dan wawancara. Instrument yang digunakan dalam penelitian ini yaitu kuesioner. Teknik yang digunakan untuk menganalisis data yaitu analisis deskriptif kualitatif dan kuantitatif.

\section{HASIL DAN PEMBAHASAN}

\section{Hasil}

Pada tahap plan ini peneliti merencanakan kebutuhan network, melakukan analisis, dan perencanaan waktu pengerjaan proyek. Selanjutnya, dilakukan pembagian alamat jaringan (Network Layer Addressing) sesuai dengan jumlah pengguna pada setiap segmen. Hal ini dilakukan agar jumlah pengguna yang terhubung pada jaringan tetap dapat dikontrol. Selain itu, pengalamatan jaringan juga diperlukan untuk melakukan dokumentasi pengalamatan, sehingga mudah dalam melakukan identifikasi apabila terjadi masalah. Pengamatan menggunakan tracert menunjukkan bahwa paket tersebut melewati beberapa langkah untuk mencapai ip google. Beberapa lompatan menyebabkan permintaan paket request time out dan pada akhir loncatan paket mengalami destination host unreachable. Ini menunjukkan bahwa ada kegagalan dalam transfer data atau paket gagal. Pengamatan menggunakan wireshark menunjukkan bahwa Conversations yang terjadi dalam komunikasi data di bagian Administrasi broadcast direkam dalam ukuran yang lumayan besar. Hal ini sering menyebabkan komunikasi data terganggu karena jaringan melemah. Jika beban terlalu berat pada network yang disebabkan oleh traffic broadcast inilah yang menyebabkan network jatuh dan menjadi tidak stabil.

Tahap desain adalah proses mengubah kebutuhan pada tahap perencanaan yang menjadi desain sistem yang benar-benar diimplementasikan. Pada tahap ini dilakukan perancangan topologi setelah dilakukan pengecekan terhadap permasalahan yang ditemukan pada tahap persiapan. Pada topologi sistem jaringan komputer SMK Negeri 2 Magelang digunakan konfigurasi VLAN. VLAN digunakan untuk membuat pembagian jaringan-jaringanya lebih spesifik. Jika VLAN yang bekerja di layer 2 akan membagi jaringan-jaringan secara lebih spesifik, pada akhirnya pembagian jaringan ini akan menjadi lebih sederhana dan teratu. Berikut topologi jaringan sebelumnya yang digunakan pada SMK Negeri 2 Magelang dan topologi yang saat ini diterapkan pada sistem jaringan komputer SMK Negeri 2 Magelang untuk memperbaiki sistem jaringan yang lama. Terlihat topologi jaringan komputer SMK Negeri 2 Magelang. Pada kasus SMK Negeri 2 Magelang, peralatan jaringan komputer dibongkar dan kabel tercabut secara tidak sengaja, meningkatkan ketidakstabilan jalur transmisi data. Dari permasalahan tersebut, digunakan teknologi VLAN untuk mengatasi permasalahan tersebut di atas, sehingga jika jaringan mengalami hambatan di kemudian hari, jaringan VLAN ini akan tetap bertahan.

Topologi jaringan komputer SMK Negeri 2 Magelang yang sering mengalami tambal sulam. Pada kasus SMK Negeri 2 Magelang, jaringan tambal sulam yang dilakukan tidak menggunakan topologi awal sebagai acuan. Jadi setelah berjalan lama dan mengalami tambal sulam secara terus menerus, jaringan yang telah terimplementasi akan menjadi kacau. Demikian pula, peralatan jaringan komputer dibongkar dan kabel tercabut secara tidak sengaja, meningkatkan ketidakstabilan jalur transmisi data. Dari permasalahan tersebut, digunakan teknologi VLAN untuk mengatasi permasalahan tersebut di atas. Jika jaringan mengalami tambal sulam di kemudian hari, maka jaringan VLAN ini akan tetap bertahan.

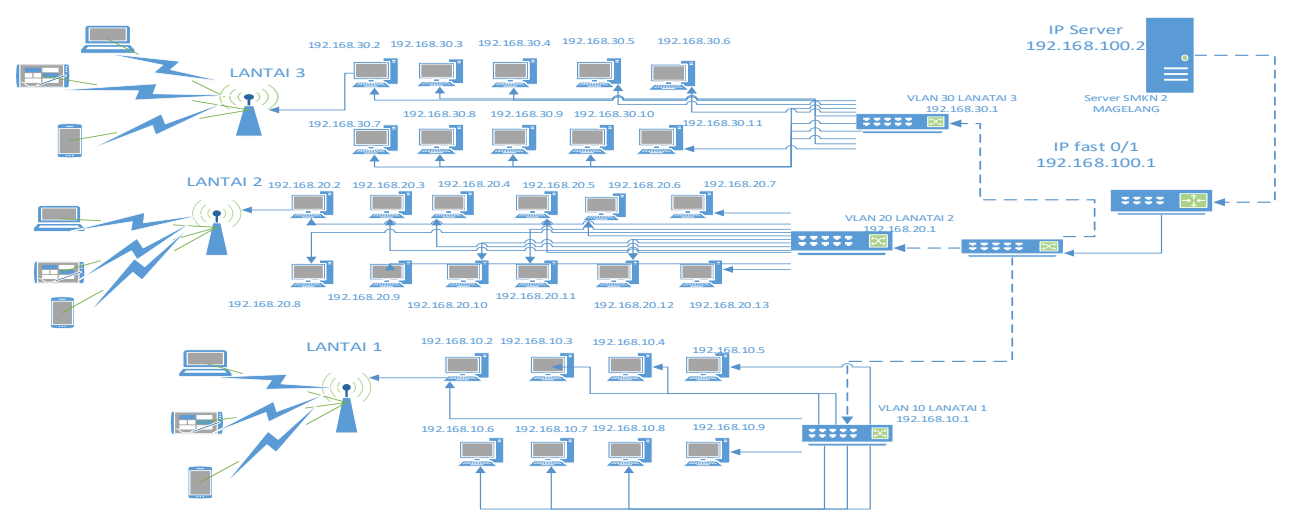

Gambar 1. Topologi VLAN 
Dalam topologi ini, VLAN digunakan untuk membagi jaringan menjadi beberapa workgroup. Dengan membagi jaringan secara logik menjadi beberapa workgroup, domain siaran dapat diatur untuk meminimalkan kemungkinan konflik IP yang berlebihan dan terjadinya tabrakan domain, membantu mengurangi tingkat vulnerebilitas dalam jaringan. Ketika skala jaringan meningkat dan traffic broadcast menjadi beban di seluruh jaringan, penggunaan VLAN ini menjadi sangat penting. Beban berlebih yang diakibatkan oleh traffic broadcast ini dapat menyebabkan jaringan menjadi hang dan tidak responsif sebelumnya. Berdasarkan topologi jaringan pada Gambar 1 maka perlu dilakukan pembagian VLAN pada setiap perangkat yang terhubung ke jaringan dan penyediaan VLAN akan disesuaikan dengan sistem yang berjalan pada topologi jaringan tersebut. Jaringan ini menggunakan IP Kelas B karena memenuhi kondisi host yang termasuk dalam jaringan komputer SMK Negeri 2 Magelang. Berikut ini adalah daftar VLAN dan ip address-nya, terdapat pada Tabel 1.

Tabel 1. Pembagian IP Address pada Jaringan VLAN

\begin{tabular}{ccccc}
\hline Perangkat & Port & IP Adress & Network & Gateway \\
\hline & VLAN 30-Lantai 3 & $192.168 .30 .1 / 24$ & 192.168 .30 .0 & 192.168 .30 .1 \\
& VLAN 20-Lantai 2 & $192.168 .20 .1 / 24$ & 192.168 .20 .0 & 192.168 .20 .1 \\
Switch & VLAN 10-Lantai 1 & $192.168 .10 .1 / 24$ & 192.168 .10 .0 & 192.168 .10 .1 \\
& FastEthernet0/3 & VLAN 30 & 192.168 .30 .0 & 192.168 .30 .1 \\
& FastEthernet0/2 & VLAN 20 & 192.168 .20 .0 & 192.168 .20 .1 \\
& FastEthernet0/1 & VLAN 10 & 192.168 .10 .0 & 192.168 .10 .1 \\
Wireless 1 & Internet & $192.168 .30 .100 / 24$ & 192.168 .30 .0 & 192.168 .30 .1 \\
Wireless 2 & Internet & $192.168 .20 .100 / 24$ & 192.168 .20 .0 & 192.168 .20 .1 \\
Wireless 3 & Internet & $192.168 .10 .100 / 24$ & 192.168 .10 .0 & 192.168 .10 .1 \\
\hline
\end{tabular}

Pada bagian Mikrotik yang digunakan untuk mengaktifkan dan menonaktifkan port yang akan digunakan atau ditetapkan pada switch yang akan dikoneksikan nantinya. Ada beberapa pengaturan terkait port yang akan digunakan. Record vlan id yang akan dibagikan ke switch sebelumnya didaftarkan terlebih dahulu. Port pada sakelar 1 digunakan sebagai trunk port, port2 switch akan menjadi mode akses vlan 10, port4 switch akan menjadi mode akses vlan 20, dan port4 switch akan menjadi akses mode oleh vlan 30, dan port lainnya Switch di sini akan bertindak dan mengatur traffic yang datang dan meninggalkan port tersebut.

Pada tahap operate inilah sebuah sistem jaringan secara keseluruhan diterapkan berdasarkan tahap design yang telah dibuat. Dalam tahap ini juga dilakukan uji coba. Pengujian dilakukan melalui ping dan wireshark dalam kondisi real-time dengan parameter pengukuran delay, jitter, packet loss, dan throughput. Pengukuran dilakukan dengan menggunakan perangkat lunak analisis jaringan Wireshark untuk menganalisis paket data dalam protokol TCP dari hasil pengujian. Waktu pengujian adalah 1 minggu dan diukur sekali sehari. Pengukuran dilakukan di empat lokasi berbeda, ya ng dianggap mewakili trafik jaringan di lingkungan nyata. Proses yang terjadi pada jaringan dapat dilihat oleh suatu software, sehingga nilai QoS pada jaringan dapat diukur. Software yang sering digunakan adalah Wireshark. Software ini dapat mengukur parameter-parameter QoS pada jaringan.

Tahap optimasi ini merupakan tahap terakhir dari metode PPDIOO. Sebenarnya, fungsi tahap ini adalah untuk mengoptimalkan sistem ketika kinerjanya tidak optimal karena adanya masalah pada sistem. Dalam penelitian ini, tahap optimize tidak akan dibahas lebih lanjut karena selama proses investigasi tidak ditemukan masalah yang mengganggu kinerja sistem. Jika sistem memiliki kelemahan, maka hal itu akan digunakan sebagai saran untuk pengembangan selanjutnya.

Pengamatan dan analisis dilakukan menggunakan topologi jaringan VLAN kabel fiber optic yang menghubungkan antara router Internet Service Provider (ISP) ke router yang ada pada SMKN 2 Magelang, sedangkan yang menghubungkan antara router ke switch setiap lantai menggunakan kabel Unshielded Twisted Pair (UTP). Kemudian switch yang ada di setiap lantai 1, 2 dan 3 menghubungkan ke perangkat komputer dibagian-bagian unit kerjanya agar terhubung dalam satu jaringan. Berikut merupakan hasil pengukuran pada ujicoba di beberapa titik dalam jaringan SMK Negeri 2 Magelang. Kebutuhan perangkat jaringan yang digunakan dalam perancangan jaringan VLAN pada SMKN 2 Megelang dapat dilihat pada Tabel 2. 
Tabel 2. Perangkat Jaringan VLAN

\begin{tabular}{cccc}
\hline No & Perangkat Jaringan & Type & Jumlah \\
\hline 1 & Router & Work & 1 Unit \\
2 & Switch & Work & 4 Unit \\
3 & Server & Work & 1 Unit \\
4 & Wireless & Work & 3 Unit \\
5 & PC & Work & 29 Unit \\
\hline
\end{tabular}

Analisis Koneksi Jaringan merupakan Analisis Round Trip Time (RTT), Packet Loss, dan Time To Live (TTL). Perancangan jaringan VLAN pada SMKN 2 Magelang akan dianalisis koneksi jaringan VLANnya untuk membuktikan dan mencari Round Trip Time, Time To Live, dan packet loss. Untuk lebih jelasnya dapat dilihat pada Tabel 3.

Tabel 3. Analisis Koneksi Jaringan

\begin{tabular}{|c|c|c|c|c|c|}
\hline \multirow{2}{*}{ JaringanVLAN } & \multirow{2}{*}{ Asal } & \multirow{2}{*}{ Tujuan } & \multicolumn{3}{|c|}{ Rata-Rata } \\
\hline & & & RTT (ms) & Packet Loss (\%) & TTL (ms) \\
\hline $\begin{array}{l}\text { VLAN 10- } \\
\text { Lantai } 1\end{array}$ & $\begin{array}{l}\text { PC 1-10, Laptop, } \\
\text { Handphone, Tablet }\end{array}$ & Server Akademik & 19,16 & 1,2 & 116 \\
\hline $\begin{array}{l}\text { VLAN 20- } \\
\text { Lantai } 2\end{array}$ & $\begin{array}{l}\text { PC 12-15, Laptop } \\
\text { Handphone, } \\
\text { Tablet }\end{array}$ & Server Akademik & 14,16 & 2,45 & 116 \\
\hline $\begin{array}{l}\text { VLAN 30- } \\
\text { Lantai } 3\end{array}$ & $\begin{array}{l}\text { PC 24-26, Laptop } \\
\text { Handphone, } \\
\text { Tablet }\end{array}$ & Server Akademik & 12,16 & 2,64 & 116 \\
\hline
\end{tabular}

Penjelasan dari Tabel 3 bahwa percobaan ping dalam simulasi ini dilakukan sebanyak 5 kali dari setiap VLAN yang berbeda terhadap server akademik yang dituju, dari hasil ping tersebut didapatkan nilai rata-rata round trip time (RTT) yang paling besar adalah 19,16 ms. Untuk nilai rata-rata packet loss atau paket yang hilang yang paling besar 2,64\% Sedangkan nilai rata-rata dari Time To Live pada saat dilakukan pengujian dalam perancangan jaringan VLAN ini sebesar 116 ms. Oleh karena itu, dari hasil ini dapat dikatakan bahwa jaringan VLAN ini sudah terkoneksi dengan baik karena setiap parameter yang diujikan nilai rata- ratanya tidak terlalu signifikan.

\section{Pembahasan}

Pemanfaatan teknologi semakin meningkat seringin perkembangan ilmu pengetahuan. Penguasaan jaringan computer seperti dasar jaringan computer dan bahasa pemograma sangat diperlukan oleh siswa jurusan jaringan computer. Jaringan computer merupakan koneksi lebih dari dua perangkan yang terhubung sehingga dapat saling bertukar data (Hertanto, 2021; Nugroho \& Kurniawan, 2018; Zaus \& Krismadinata, 2018). Jika perangkat dapat bertukar daya dan berbagi daya maka dapat dikatakan bahwa jaringan computer terhubung dengan baik. Kegiatan bertukar data menjadi sangar efisian dari segi waktu dan dapat dilaksanakan di mana pun (Gunawan et al., 2021; Shandilya et al., 2022). Seiring dengan tingginya tingkat kebutuhan, maka semakin banyaknya pengguna jaringan yang menginginkan jaringan yang dapat melayani secara maksimal dari segi keamanan. Salah satunya dengan menggunakan Quality of Service. Quality of Service (QoS) adalah teknologi yang memungkinkan administrator jaringan menangani berbagai efek kemacetan pada aliran paket berbagai layanan untuk mengoptimalkan penggunaan sumber daya jaringan alih-alih meningkatkan kapasitas fisik jaringan (Kumar et al., 2021; Slimen et al., 2021). Tujuan mekanisme QoS adalah untuk memengaruhi setidaknya satu dari empat parameter dasar QoS yang telah ditentukan (Hailu et al., 2020).

Seorang administrator jaringan akan dapat memiliki kontrol terhadap setiap port switch dan user dengan cara membuat virtual local area network (VLAN) dan menciptakan banyak broadcast. Dengan demikian, user tidak akan bisa menghubungkan kabel ke sembarang port switch dan memperoleh akses sumber daya jaringan (Nourildean et al., 2021; Tulloh et al., 2015). Dalam jaringan Virtual Local Area Network (VLAN) yang menggunakan switch tradisional, administrator jaringan harus mengonfigurasi setiap perangkat keras jaringan yang terhubung ke jaringan. Konfigurasi harus mengikuti setiap konfigurasi perangkat keras. Setiap perangkat keras jaringan memiliki metode konfigurasi yang berbeda tergantung pada vendor perangkat keras. Konsep VLAN (Virtual Area Network) banyak keuntungan yang dapat diperoleh dari konsep tersebut. Dengan VLAN (Virtual Area Network), memungkinkan seseorang membuat banyak jaringan komputer (segmentasi) dan mendistribusikan hanya menggunakan saluran 
distribusi media dan dapat untuk menghubungkan jaringan area lokal (LAN) tanpa mengikuti lokasi geografis (Bhardwaj \& Sharma, 2018; Nourildean et al., 2021; Tulloh et al., 2015). Jaringan VLAN pada penelitian ini sudah terkoneksi dengan baik.

\section{SIMPULAN}

Hasil dari simulasi peracangan jaringan virtual local area network (VLAN) ini didapatkan nilai rata-rata tertinggi. Nilai rata-rata packet loss dalam simulasi ini $2,64 \%$, sedangkan nilai rata-rata time to live sebesar 116 ms. Dari hasil pengujian diketahui ini bahwa perancangan jaringan virtual local area network (VLAN) ini dapat atau layak untuk diimplemantasikan.

\section{DAFTAR RUJUKAN}

Bhardwaj, T., \& Sharma, S. C. (2018). Cloud-WBAN: An Experimental Framework for Cloud-enabled Wireless Body Area Network with Efficient Virtual Resource Utilization. Sustainable Computing: Informatics and Systems, 20. https://doi.org/10.1016/j.suscom.2018.08.008.

Burik, A. (2021). Using Technology to Help Students Set, Achieve, and Publicize Goals. Adult Literacy Education: The International Journal of Literacy, Language, and Numeracy, 3(1), 83-89. https://doi.org/10.35847/aburik.3.1.83.

Dina, A. S., \& Manivannan, D. (2021). Intrusion Detection Based on Machine Learning Techniques in Computer Networks. Internet of Things, 16. https://doi.org/10.1016/j.iot.2021.100462.

Gunawan, I. K., Sukmana, H. T., \& Ardianto, A. Y. (2021). Blockchain Technology as A Media for Sharing Information that Generates User Access Rights and Incentives. Blockchain Frontier Technology, 1(01), 44-55. https://doi.org/10.3389/fbloc.2020.497985.

Hailu, D. H., Lema, G. G., Gebrehaweria, B. G., \& Kebede, S. H. (2020). Quality of Service (QoS) Improving Schemes in Optical Networks. Heliyon, 6(4). https://doi.org/10.1016/j.heliyon.2020.e03772.

Hertanto, D. B. (2021). Upaya Peningkatan Kualitas Kuliah Jaringan Komputer melalui Penerapan Media Pembelajaran Packet Tracer 5.0. Jurnal Pendidikan Teknologi Dan Kejuruan Dan Kejuruan, 20(1). https://doi.org/10.21831/jptk.v20i1.7753.

Kumar, B. V., Ahmed, S. M., \& Prasad, M. N. G. (2021). Efficient Method to Identify Hidden Node Collision and Improving Quality-of-Service (QoS) in Wireless Sensor Networks. Materials Today: Proceedings. https://doi.org/10.1016/j.matpr.2021.05.498.

Li, X., Ji, L., Zhu, H., Li, P., Jia, X., \& Li, C. (2021). Cellular Automata-Based Simulation of Cross-Space Transmission of Energy Local Area Network Risks: A Case Study of A Power Supply Station in $\begin{array}{lllll}\text { Beijing. Sustainable Energy, Grids and } & \end{array}$ https://doi.org/10.1016/j.segan.2021.100521.

Moedjahedy, J. (2016). Implementasi Point to Point Jaringan Internet Nirkabel Di SMA Universitas Klabat. Gogita Smart Journal, 2(2). https://doi.org/10.31154/cogito.v2i2.33.240-249.

Nourildean, S. W., Salih, A. M., \& Othman, K. M. Z. (2021). AODV, DSR and OLSR Routing Protocols Investigation on Virtual Local Area Network. Materials Today: Proceedings. https://doi.org/10.1016/j.matpr.2021.01.089.

Nugroho, K., \& Kurniawan, A. Y. (2018). Uji Performansi Jaringan Menggunakan Kabel UTP dan STP. Jurnal Elkomika, 5(1). https://doi.org/10.26760/elkomika.v5i1.48.

Ogelman, H. G., Gungor, H., Korukcu, O., \& Sarkaya, H. E. (2018). Examination of the Relationship Between Technology Use of 5-6 Year-Old Children and Their Social Skills and Social Status. Early Child Development and Care, 188(2), 168-182. https://doi.org/10.1080/03004430.2016.1208190.

Qiang, T. (2021). Engineering Design of Electronic Fence System Based on Intelligent Monitoring and Wireless Local Area Network. Alexandria Engineering Journal. https://doi.org/10.1016/j.aej.2021.08.019.

Rohman, Q. A. H. H., \& Salahuddin, N. S. (2018). Rancang Bangun Prototipe Mobil Penjelajah dengan Kendali Jarak Jauh melalui Jaringan Wi-Fi Berbasis Antarmuka Web. Teknika, 7(1). https://doi.org/10.34148/teknika.v7i1.79.

Rupilele, frits gerit john, \& Palilu, A. (2019). Rancang Bangun Sistem Informasi Manajemen Pengaduan Masyarakat dan Monitoring Kinerja Akademik Perguruan Tinggi. Jurnal Sisfokom, 8(2). https://doi.org/10.32736/sisfokom.v8i2.672.

Schrammel, H., Kelz, J., Gruber-Glatzl, W., Halmdienst, C., \& Schröttner, J. (2021). Increasing Flexibility towards a Virtual District Heating Network. Energy Reports, 7(4). https://doi.org/10.1016/j.egyr.2021.08.075. 
Shandilya, S. K., Upadhyay, S., Kumar, A., \& Nagar, A. K. (2022). AI-Assisted Computer Network Operations testbed for Nature-Inspired Cyber Security Based Adaptive Defense Simulation and Analysis. Future Generation Computer Systems, 127. https://doi.org/10.1016/j.future.2021.09.018.

Slimen, Y. Ben, Balcerzak, J., Pagès, A., Agraz, F., Spadaro, S., \& Koutsopoulos, K. (2021). Quality of Perception Prediction in 5G Slices for E-Health Services using User-Perceived QoS. Computer Communications, 178. https://doi.org/10.1016/j.comcom.2021.07.002.

Solikin, I. (2017). Penerapan Metode PPDIOO dalam Pengembangan LAN dan WLAN. Jurnal Teknologi Dan Informatika, 7(1). http://ojs.palcomtech.ac.id/index.php/teknomatika/article/view/34.

Toyoda, Y., Muranaka, A., Kim, D., \& Kanegae, H. (2021). Framework for Utilizing Disaster Learning Tools Classified by Real and Virtual Aspects of Community Space and Social Networks: Application to Community-Based Disaster Risk Reduction and School Disaster Education on Earthquakes in Japan for During- and Pos. Progress in Disaster Science, 12. https://doi.org/10.1016/j.pdisas.2021.100210.

Tulloh, R., Negara, R. M., \& Hidayat, A. N. (2015). Simulasi Virtual Local Area Network (VLAN) Berbasis Software Defined Network (SDN) Menggunakan POX Controller. Jurnal Infotel, 7(2). https://doi.org/10.20895/infotel.v7i2.40.

Wongkar, S., Sinsuw, A., \& Najoan, X. (2015). Analisis Implementasi Jaringan Internet dengan Menggabungkan Jaringan Lan dan Wlan di Desa Kawangkoan Bawah Wilayah Amurang II. Jurnal Teknik Elektro Dan Komputer, 4(6), 62-68. https://doi.org/10.35793/jtek.4.6.2015.10400.

Zaus, M. A., \& Krismadinata, K. (2018). Suatu Kajian Literatur Masalah-Masalah yang Dihadapi dalam Mata Kuliah Jaringan Komputer. INVOTEK: Jurnal Inovasi Vokasional Dan Teknologi, 18(2), 1-8. https://doi.org/10.24036/invotek.v18i2.263.

Zhu, X., \& Luo, S. (2021). The Influence of Computer Network Technology on National Income Distribution Under the Background of Social Economy. Computer Communications, 177. https://doi.org/10.1016/j.comcom.2021.06.025. 